nieuws- en forumsfeer af. In tien hoofdstukken tracht hij het journalistieke en forumdiscours te analyseren door misdaadsagen te benaderen als retorische constructies en zet daarmee een stap in de goede richting van (journalistieke) gewaarwording over dit soort verhalen. Met de woorden 'geen verhaal zonder moraal' (p. 278) plaatst Burger terecht een kritische noot bij de huidige vertrouwenscrisis die heerst tussen het publiek en de mainstream media. De analyse van de twee case studies toont immers aan dat forumdeelnemers het gezag van de nieuwsmedia vaak niet erkennen. De media kunnen een verhaal als dat van de Smileybende resoluut ontkennen, maar op online forums gaat de discussie desondanks voort. De onderzoeker legt hiermee een duidelijke kloof tussen het vernaculaire domein en het domein van het nieuws bloot.

Ondersteund door academische bevindingen uit de journalistieke en sociologische hoek (o.a. Herbert Gans en Michael Schudson), wijt Burger deze kloof deels aan het geijkte bronnengebruik van journalisten. Aangezien die laatste meestal terugvallen op een beperkt aantal officiële en volgens nieuwsmakers meer betrouwbare bronnen, worden vernaculaire uitingen over het algemeen weinig als nieuwsbron benut. Het is deze journalistieke vooronderstelling die door de resultaten van dit onderzoek een stevige knauw krijgt. Discussies op publieke forums zouden volgens Burger immers meer kunnen zijn voor journalisten dan louter illustratieve voorbeelden. Journalistieke opleidingen zouden er baat bij hebben hun studenten in aanraking te brengen met onder meer retoriek, de constructie van sociale problemen door de media en narratieve folklore, aldus Burger.

Het hier gebruikte retorische analysemodel zou in de toekomst eveneens bruikbaar kunnen zijn in onderzoek naar de invloed van sociale media-interacties op de journalistieke praktijk. Burger focust in zijn onderzoek enkel op webforums en maakt bijgevolg amper melding van de mogelijkheden die hedendaagse discussieplatformen als Facebook en Twitter kunnen bieden voor modern sagenonderzoek. De vraag kan zelfs gesteld worden in hoeverre webforums nog relevant zijn wanneer trends zoals '\#dtv' (durf te vragen) op de microblog Twitter deels de functie van forums overnemen.

Burgers werk stemt duidelijk tot nadenken over de invloed van sterke verhalen op de journalistieke praktijk, zeker nu die professie meer dan ooit geconfronteerd wordt met niet-institutionele uitingen via het internet. Journalisten in spe zouden ongetwijfeld geholpen zijn met een meer divers onderbouwd lessenpakket dat hen reeds wijst op de valkuilen van sagen. Kortom, Monsterlijke Verhalen is een boeiend interdisciplinair proefschrift geworden dat de nieuwsgierigheid wekt naar een verdere verkenning van vernaculaire uitingen en de wisselwerking ervan met journalistieke waarden.

\section{Cara Brems}

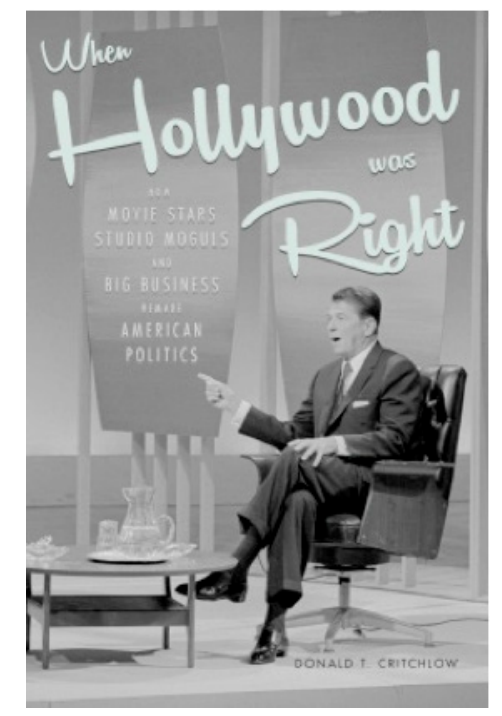

\section{Donald T. Critchlow}

When Hollywood Was Right. How Movie Stars, Studio Moguls, and Big Business remade American Politics

Cambridge (Cambridge University Press) 2013, 224 pp., ill., ca. € 23,-, ISBN 978 ० 52I I99I8 6 
Dit boek plaatst zich in een rijke traditie van literatuur en onderzoek naar de politiekinstitutionele geschiedenis van Hollywood, meer in het bijzonder de relatie tussen de Amerikaanse filmindustrie en de Republikeinse Partij. In When Hollywood Was Right vertelt Donald T. Critchlow het verhaal van de wederopstanding van de Grand Old Party (GOP) vanaf de jaren I930 tot en met het presidentschap van Ronald Reagan (I98I-I989). Als historicus met als specialisme de twintigste-eeuwse Amerikaanse politiek, concentreert Critchlow zich niet zozeer op de bekende politieke overlegstructuren, maar wel op de praktische uitbouw van informele netwerken en allianties tussen Republikeinse politici en conservatieve zakenlui, studiobonzen, regisseurs, filmsterren en andere celebrities in en rond Hollywood. Centraal in Critchlows verhaal staat de idee dat studio moguls, filmproducenten, -regisseurs en -acteurs zoals John Wayne, Gary Cooper, Bob Hope, Charlton Heston of Robert Taylor niet alleen zorgden voor glamour en glitter tijdens verkiezingscampagnes, maar dat ze een veel actievere rol speelden in de reorganisatie van de GOP. Sommigen engageerden zich openlijk met de partij (мGм-baas Louis B. Mayer was vice-chairman en vervolgens chairman van de California Republican Party in de periode van I93I tot I933) of stelden zich kandidaat voor politieke functies, zelfs op het hoogste federale niveau met senator en later president Reagan als ultiem voorbeeld. Andere acteurs steunden lokale initiatieven van de partij in Californië of financierden op een meer substantiële wijze de structurele uitbouw van de Gop. Cruciaal was de rol van bekende producenten, regisseurs en acteurs zoals Cecil B. DeMille en George Murphy, die zich ontpopten tot invloedrijke fundraising liaisons tussen Hollywood, de politiek en de zakenwereld.

When Hollywood Was Right houdt zich ver van theoretische bespiegelingen over de relatie tussen politiek en media, en trekt resoluut de kaart van feitelijke, op heel wat archiefonderzoek gebaseerde analyses. Ook laat Critchlow na om het veld waarin zijn boek zich begeeft te beschrijven, of om in dialoog te treden met ander werk dat de afgelopen jaren op dit terrein is verschenen. Toch is When Hollywood Was Right een interessante bijdrage, niet in het minst omdat het boek de populaire mythe doorprikt van Hollywood als een broedplaats van progressieve politieke krachten, een mythe die vooral gevoed werd door acteurs en andere Hollywood celebs die hun voorkeur voor Democratische politici publiekelijk uitspraken.

Een onderliggende stelling van het boek is dat de alliantie tussen de GOP en conservatieve krachten binnen de filmindustrie een katalyserende rol heeft gespeeld in de 'mediatisering' van het politieke bedrijf, of dat 'California's media-driven politics would eventually become a national model' (p. 3). De alliantie zorgde ervoor dat de politieke arena marketingprincipes uit Hollywood en zijn star system overnam - niet in het minst de promotie van politieke sterren, media-advies en intensieve mediatraining. Op een ruimer niveau zorgde de alliantie voor een sterke verwevenheid tussen politiek en celebrity culture. Interessant in dit opzicht is het vierde hoofdstuk, dat handelt over de opmars van de jonge Richard Nixon, die later senator (voor de staat California, I950-I953), vice-president (I953-I96I) en president (I969-I974) van de Verenigde Staten werd. In zijn boek beschrijft Critchlow hoe 'media-savvy' en hoe begeesterd Nixon wel was door Hollywood. Nixon, zo geeft Critchlow aan, mag nu dan al geboekstaafd staan als de presidentskandidaat die in 1960 de verkiezingen verloor in een voor hem nefast televisiedebat met John F. Kennedy, maar in werkelijkheid was hij zijn tijd ver vooruit in de manier waarop hij met moderne massamedia omsprong.

Zeer lezenswaardig zijn ook de eerste twee hoofdstukken waar Critchlow vertelt hoe de plaatselijke Republikeinse Partij het debâcle van 
de jaren i930 trachtte te verwerken, meer bepaald na de verpletterende verkiezingsoverwinning van Franklin D. Roosevelt in I936 toen de GOP geheel ontredderd en bijna gedecimeerd werd. Met veel oog voor detail en anekdotiek beschrijft Critchlow hoe conservatieve krachten binnen de filmindustrie, de zakenwereld en de politiek elkaar vonden in hun afkeer van progressieve organisaties zoals linkse vakbonden. Het bindmiddel was een amalgaam van conservatieve waarden rond patriottisme, individualisme, 'free enterprise' en anticommunisme.

Het belangrijkste hoofdstuk in het boek behandelt de periode van de blacklist en de heksenjacht, grofweg vanaf I947 tot het einde van de jaren I950 (Hoofdstuk 3). De literatuur over deze duistere periode in de Amerikaanse politieke en mediageschiedenis is bijzonder omvangrijk, maar toch slaagt Critchlow erin enkele nieuwe inzichten te verschaffen, niet in het minst over de rol van de communistische partij en de invloed van linkse vakbonden en andere organisaties in Hollywood.

De laatste twee hoofdstukken behandelen de periode vanaf de jaren I960 (Hoofdstuk 5) met daarin een glansrol voor de 'grote communicator' Ronald Reagan (Hoofdstuk 6). In dit deel doorprikt Critchlow de mythe dat Reagan een politieke handpop was en dat zijn politieke aspiraties pas groeiden toen zijn carrière als acteur taande. Critchlow beschrijft Reagan als een politiek dier, die eerst Democratische sympathieën had, maar na zijn huwelijk met Nancy Davis gaandeweg onder invloed kwam van de Gop. Met Reagan, die een uitermate charismatische spreker was, nam de politiek-ideologische visie van de Hollywood Right het roer van het land over. Reagan stond immers symbool voor een 'anticommunist, patriotic, small-government vision [that] became the prevailing philosophy of the national Republican Party' (p. 213).

When Hollywood Was Right is een vernieuwende bijdrage tot de politieke geschiedenis van Hollywood, vooral omdat het een gedetailleerde en genuanceerde visie biedt op de informele netwerken achter de relatie tussen de Republikeinse Partij en de Amerikaanse filmindustrie. Een kritische kanttekening is dat het boek hier en daar wat slordigheden bevat. Zo schrijft Critchlow bij voorbeeld dat Fritz Lang een 'German refugee' was (p. 3I; Lang was Oostenrijkse regisseur) en spelt hij de naam van regisseur George Stevens verkeerd ('Stephens', p. I03). Ook bezondigt de auteur zich soms aan overdrijvingen zoals de uitspraak dat Gary Cooper 'Hollywood's most popular and highly paid actor' was (p. 36), alsofClark Gable en andere succesvolle acteurs niet bestonden. Deze opmerkingen staan echter niet in de weg dat When Hollywood Was Right op een boeiende wijze onderstreept hoezeer Hollywood (en bij uitbreiding mediacultuur) een politieke strijdplaats was (en vermoedelijk vandaag nog steeds is).

\section{Daniel Biltereyst}

